\title{
Metrology in the National Agricultural Technology Institute (INTA)
}

\author{
Gomez, Mario ${ }^{1}$ - Kremer, Raul - Slepetis, Cristina \\ ${ }^{1}$ Laboratory of Proficiency Tests, Standards and Metrology - Process and Quality Management - INTA \\ Av. Chile 460, Buenos Aires City, Argentina
}

Key Words: calibration, research, government agency, measurement

\section{INTRODUCTION}

The National Institute of Agricultural Technology (INTA) is an Argentinean state agency. It was created in 1956 in order to "promote and strength the development of agricultural research and extension, accelerating the benefits of these basic functions: the modernization and improvement of agrarian company and rural life." The main aim of INTA is to contribute to the competitiveness of the agricultural, forestry and agro-industrial sector throughout the country, in a context of environmental and social sustainability. In the Institutional Strategic Plan 2005-2015 and 2015-2025 it has adopted the international models of ISO Standards to establish its Quality Management Systems (QMS), allowing it to demonstrate a commitment to quality and excellence in the services provided. When an organization works under determined QMS -ISO 17025- must demonstrate proficiency to produce technically valid results. Consequently, all equipment that has a significant effect on the accuracy or validity of the results: must be calibrated before use and must be periodically reviewed or maintained. These operations have a high degree of outsourcing, with significant costs and logistical problems. To solve these problems, an area of Metrology was established in INTA. This area contributes to the compliance in the measurement processes in laboratories.

\section{DEVELOPMENT}

The objectives of the metrology area are:

- Promote internal control of equipment and instruments.

- Increase awareness of the importance of accurate measurements and their impact on results.

- Training of personnel to carry out calibrations in their own laboratory or in the laboratory of Metrology.

- Optimize government resources.

To achieve these objectives, the Metrology area carries out the following activities:

- Development of calibration programs

- Training of personnel in Metrology and calibration software.

- Acquisition of equipment and standards traceable to national and international standards.

- Creation of the Proficiency Testing, Standards and Metrology Laboratory (LEAPMI).

- Implementation of a Quality Management System based on ISO 17025 in the LEAPMI and accreditation with the Argentine Accreditation Body. 


\section{MATERIALS AND METHODS}

In the development of the area of Metrology, the information obtained during the study period of the following subjects was compiled:

- Procedures for the development of calibration software and its validation.

- Training in metrology and calibration

- Technical capacity of personnel responsible for calibration

- Acquisition, maintenance and calibration of standard equipment, traceable nationally and internationally.

- Calibrations performed at home

- Experts enabled by magnitude

- Process of implementation and accreditation of metrology laboratories

- Impact on saving monetary resources of INTA

An analysis of this information was made and presented in a schematic way according to the objectives of the area. The degree of compliance with the objectives was evaluated.

\section{RESULTS AND DISCUSSION}

\section{A) Development of calibration programs}

The design of the calibration software that allows calibrating in a few minutes without the need of making any staff calculation was design. The software was designed in Excel and was based on internationally accepted calibration procedures. Chronologically the development of the software was:

- 2005: balance calibration software (HE-CB)

- 2009: volumetric calibration software (HE-CV)

- 2011: thermometers calibration software (HE-CT)

- 2015: weights calibration software (HE-CP)

\section{B) Training of personnel in Metrology and calibration software.}

In the period 2005-2016, the area performed 17 courses. Table 1 presents a summary of the courses, broken down by methodology (distance or classroom) and metrological magnitude. $51 \%$ of the training was given in one classroom and the remaining $49 \%$ as a distance learning course. In the period, 348 were formed in metrology. 
Table 1. Number of courses organized by the Metrology area and number of trained persons by subject in the period 2005-2016

\begin{tabular}{|c|c|c|c|c|c|c|}
\hline \multirow{2}{*}{ Ref } & \multirow{2}{*}{$\begin{array}{c}\text { Number of } \\
\text { persons }\end{array}$} & \multicolumn{2}{|c|}{ Mode } & \multicolumn{3}{|c|}{ Magnitude } \\
\hline & & Classroom & Virtual & $\begin{array}{c}\text { Mass } \\
\text { (balances) }\end{array}$ & Volume & Temperature \\
\hline Imyza 2005 & 26 & * & & * & & \\
\hline PROCADIS 1 & 45 & & * & * & & \\
\hline PROCADIS 2 & 19 & & * & * & & \\
\hline PROCADIS 3 & 29 & & * & * & & \\
\hline CA1105 & 19 & * & & * & * & \\
\hline CA1111 & 15 & * & & * & * & \\
\hline CA1211 & 14 & * & & * & * & \\
\hline CA1222 & 19 & * & & & & * \\
\hline CA1312 & 20 & * & & * & * & * \\
\hline CA1318 & 27 & * & & * & * & \\
\hline CA1403 & 9 & & * & * & & \\
\hline CA1404 & 16 & & * & * & * & * \\
\hline CA1405 & 16 & * & & & & \\
\hline CA1501 & 15 & * & & * & * & * \\
\hline CA1503 & 22 & & * & * & * & * \\
\hline CA1505 & 28 & * & & * & * & \\
\hline CA1602 & 9 & & * & & * & \\
\hline TOTAL & 348 & 10 & 7 & 14 & 10 & 5 \\
\hline
\end{tabular}

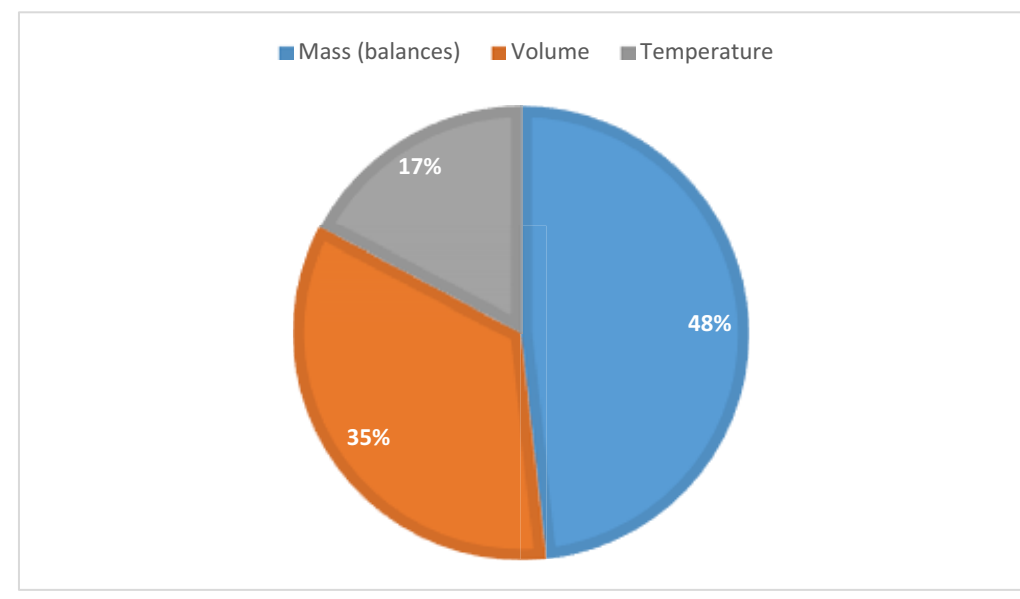

Fig. 1. Distribution of courses and calibration training for each magnitude in the period $2005-2016$

If we evaluate the effectiveness of formation and training done by measuring the amount of authorized agents during this period, we observe that nowadays we have an overall the 102 agents, 56 allowed to calibrated balances, 36 volumetric items and 10 thermometer (Fig.2). 


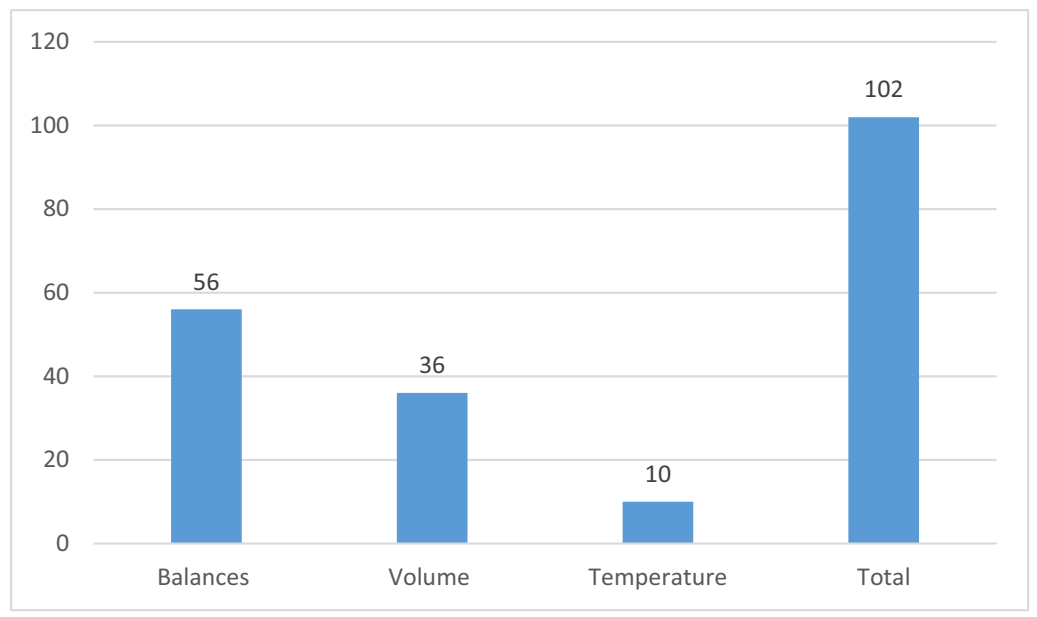

Fig. 2. Number of students rated as calibrator for each magnitude

\section{C) Acquisition of equipment and standards traceable to national and international standards}

In order to grant traceability to INTA, during the period from 2011 to 2015 the Metrology area acquired a series of standards and measuring equipment. All were identified univocally. Periodically and according to an annual calibration program, the standards and instruments are calibrated in calibration laboratories accredited with the best national measurement capacity or at the National Institute of Metrology (INTI).

In the case of balances and thermometers of less accuracy, they are calibrated by the Metrology laboratory itself.

Table 2 summarizes the list of equipment and measurement standards

Table 2: Equipment Master List Laboratory of Proficiency Tests, Standards and Metrology

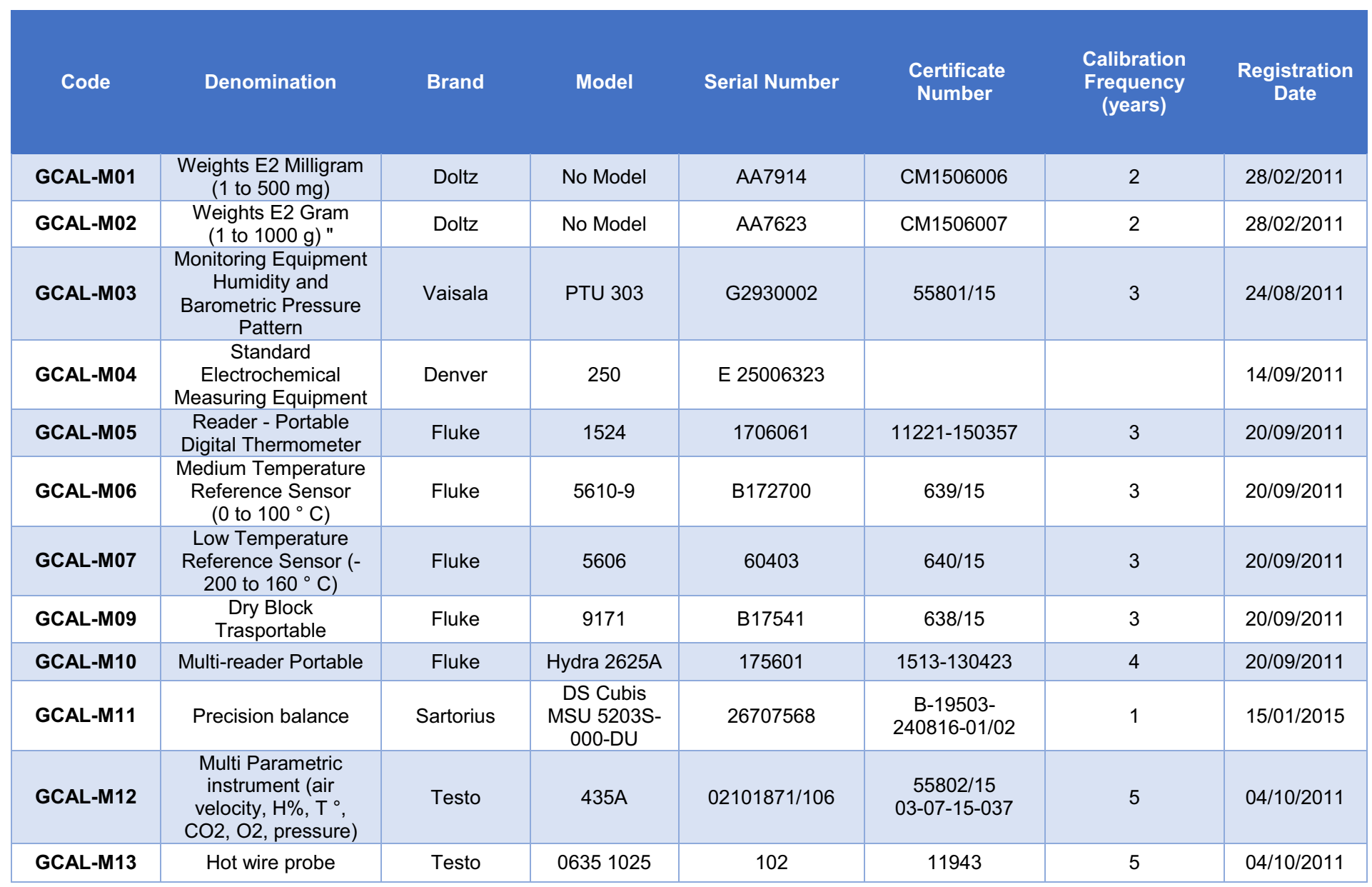




\begin{tabular}{|c|c|c|c|c|c|c|c|}
\hline GCAL-M14 & Air quality probe & Testo & 06321535 & $10240887 / 108$ & $\begin{array}{c}55802 / 15 \\
03-07-15-037\end{array}$ & 5 & $04 / 10 / 2011$ \\
\hline GCAL-M15 & $\begin{array}{l}\text { Thermocouple Type } \\
\text { "J" }\end{array}$ & Diamore & "J" & - & $\begin{array}{c}\text { T-21066-030217- } \\
01 \\
\text { T-21066-060217- } \\
01\end{array}$ & 3 & $27 / 12 / 2011$ \\
\hline GCAL-M16 & $\begin{array}{l}\text { Thermocouple Type } \\
\text { "J" }\end{array}$ & Diamore & "J" & - & $\begin{array}{c}\text { T-21066-030217- } \\
02 \\
\text { T-21066-060217- } \\
02\end{array}$ & 3 & $27 / 11 / 2011$ \\
\hline GCAL-M18 & $\begin{array}{c}\text { Thermocouple Type } \\
\text { "J" }\end{array}$ & Diamore & "J" & - & $\begin{array}{c}\text { T-21066-030217- } \\
04 \\
\text { T-21066-060217- } \\
04\end{array}$ & 3 & $27 / 11 / 2011$ \\
\hline GCAL-M19 & $\begin{array}{l}\text { Thermocouple Type } \\
\text { "J" }\end{array}$ & Diamore & "J" & - & $\begin{array}{c}\mathrm{T}-21066-030217- \\
05 \\
\mathrm{~T}-21066-060217- \\
05\end{array}$ & 3 & $27 / 12 / 2011$ \\
\hline GCAL-M21 & $\begin{array}{l}\text { Thermocouple Type } \\
\text { "J" }\end{array}$ & Diamore & "J" & - & $\begin{array}{c}\text { T-21066-030217- } \\
07 \\
\text { T-21066-060217- } \\
07\end{array}$ & 3 & $27 / 12 / 2011$ \\
\hline GCAL-M22 & $\begin{array}{l}\text { Thermocouple Type } \\
\text { "J" }\end{array}$ & Diamore & "J" & - & $\begin{array}{c}\text { T-21066-030217- } \\
08 \\
\text { T-21066-060217- } \\
08\end{array}$ & 3 & $27 / 11 / 2011$ \\
\hline GCAL-M23 & $\begin{array}{l}\text { Thermocouple Type } \\
\text { "J" }\end{array}$ & Diamore & "J" & - & $\begin{array}{c}\text { T-21066-030217- } \\
09 \\
\text { T-21066-060217- } \\
09\end{array}$ & 3 & $27 / 12 / 2011$ \\
\hline GCAL-M28 & Weight E2 $500 \mathrm{~g}$ & Doltz & No Model & AA9064 & 15202-p0912 & 5 & $01 / 03 / 2013$ \\
\hline GCAL-M29 & Weight E2 $500 \mathrm{~g}$ & Doltz & No Model & AA9065 & 15202-p0912 & 5 & $01 / 03 / 2013$ \\
\hline GCAL-M30 & $\begin{array}{l}\text { Weights E2 (1 a } 500 \\
\mathrm{mg})(1 \mathrm{~g}, 2 \mathrm{~g})\end{array}$ & Doltz & No Model & AA9058 & 15196-p0912 & 5 & $01 / 03 / 2013$ \\
\hline GCAL-M31 & Weight E2 1 mg & Doltz & No Model & AA9059 & 15197-p0712 & 5 & $01 / 03 / 2013$ \\
\hline GCAL-M32 & Weight E2 $1 \mathrm{mg}$ & Doltz & No Model & AA9060 & 15198-p0712 & 5 & $01 / 03 / 2013$ \\
\hline GCAL-M33 & E1 Weight Set & Doltz & No Model & AA9057 & $\begin{array}{l}\text { Verificación } \\
\text { primitiva INTI }\end{array}$ & 5 & $01 / 03 / 2013$ \\
\hline GCAL-M38 & Comparator Balance & $\begin{array}{l}\text { Mettler } \\
\text { Toledo }\end{array}$ & XP505 & B340851793 & $\begin{array}{c}\text { B-19503- } \\
240816-03 / 04\end{array}$ & 1 & $01 / 03 / 2014$ \\
\hline GCAL-M39 & $\begin{array}{l}\text { Liquid Glass } \\
\text { Thermometer }\end{array}$ & LUFT & No Model & - & $\begin{array}{c}\text { T-21066-300916- } \\
01\end{array}$ & 2 & $01 / 03 / 2014$ \\
\hline GCAL-M40 & $\begin{array}{l}\text { Liquid Glass } \\
\text { Thermometer }\end{array}$ & LUFT & No Model & - & $\begin{array}{c}\text { T-21066-300916- } \\
02\end{array}$ & 2 & $01 / 03 / 2014$ \\
\hline
\end{tabular}




\section{D) Creation of the Proficiency Testing, Standards and Metrology Laboratory (LEAPMI).}

At the beginning of 2011 was created the Laboratory of Proficiency Tests, Standards and Metrology in Process Management and Quality. In the laboratory, the training of the calibrators in the different magnitudes is carried out. Currently the laboratory carries out calibrations of electronic balances, volumetric instruments, thermometers, weights, isothermal environment characterization and laminar flow and biosafety verification.

If we analyze the number of calibrations of electronic balances, volumetric instruments, thermometers and weights performed in the period 2011 to 2016 we observe in Fig. 3 a significant increase in the number of calibrations performed in the last period. Este incremento se observó con mayor notoriedad desde el año 2014 a 2016 . Siendo el año 2014 el que mostró un incremento del 130 \% más de calibraciones, que el año 2013.

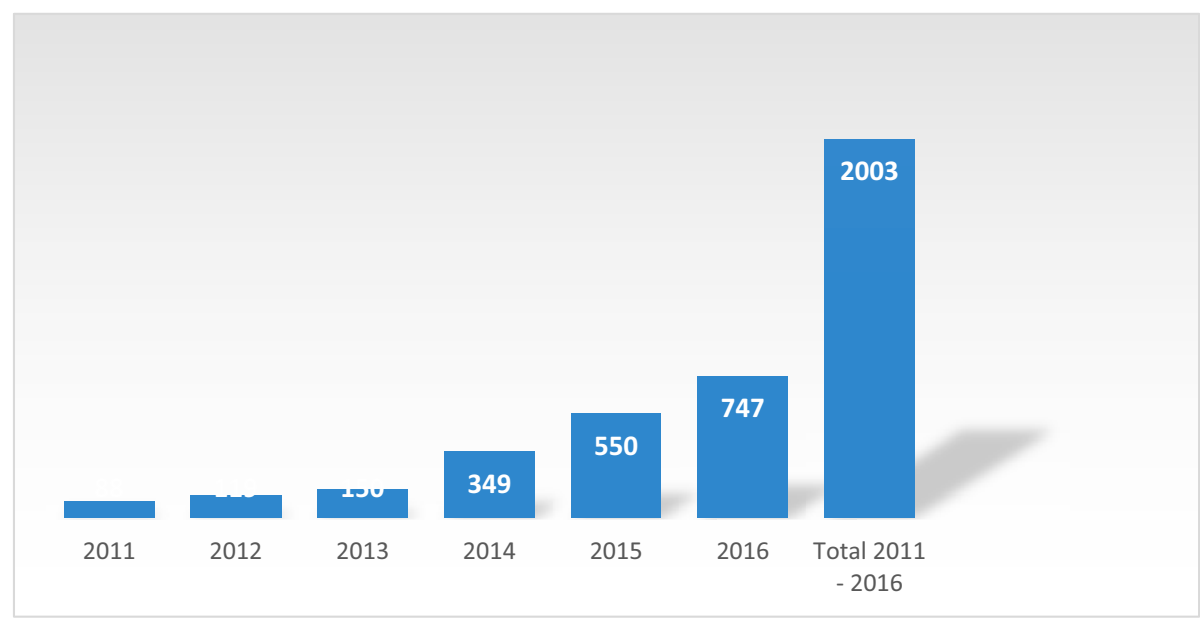

Fig. 3. Number of calibrations performed for years in the period $2011-2016$

The distribution of calibrations by magnitudes showed that $46 \%$ (926) of the calibrations were made to volumetric materials, $33 \%(662)$ to thermometers, $19 \%(370)$ to electronic balance and $2 \%(45)$ to weights (Fig. 4)

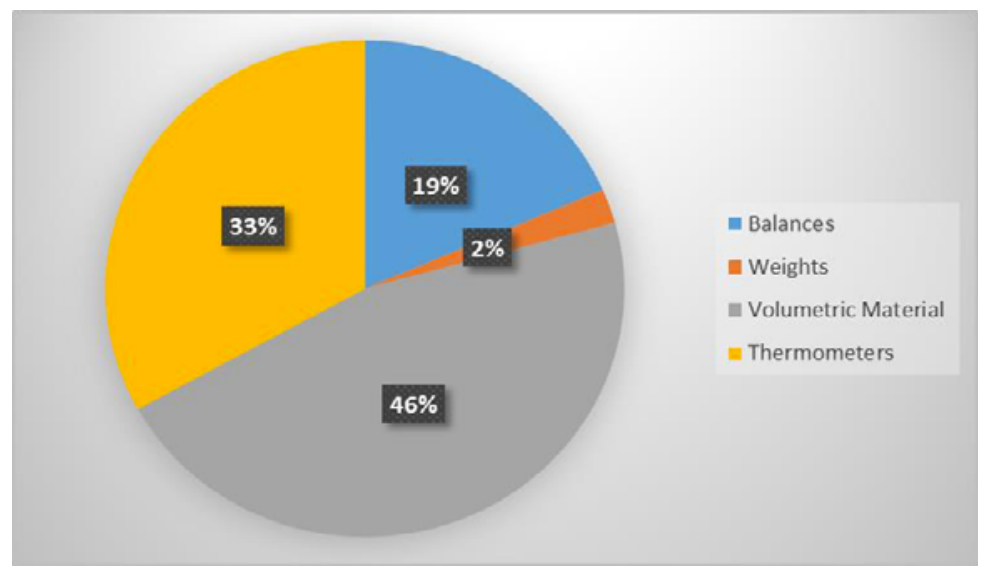

It was observed that the calibration distribution has been maintained during the period 2011-2016. Only in 2013 and 2014 did the number of calibrations of electronic balance reduced. The reason for this decline was that weights were not available because LEAPMI was in the process of being accredited and furthermore they were sent to recalibration according to the calibration program. (Fig. 5). 


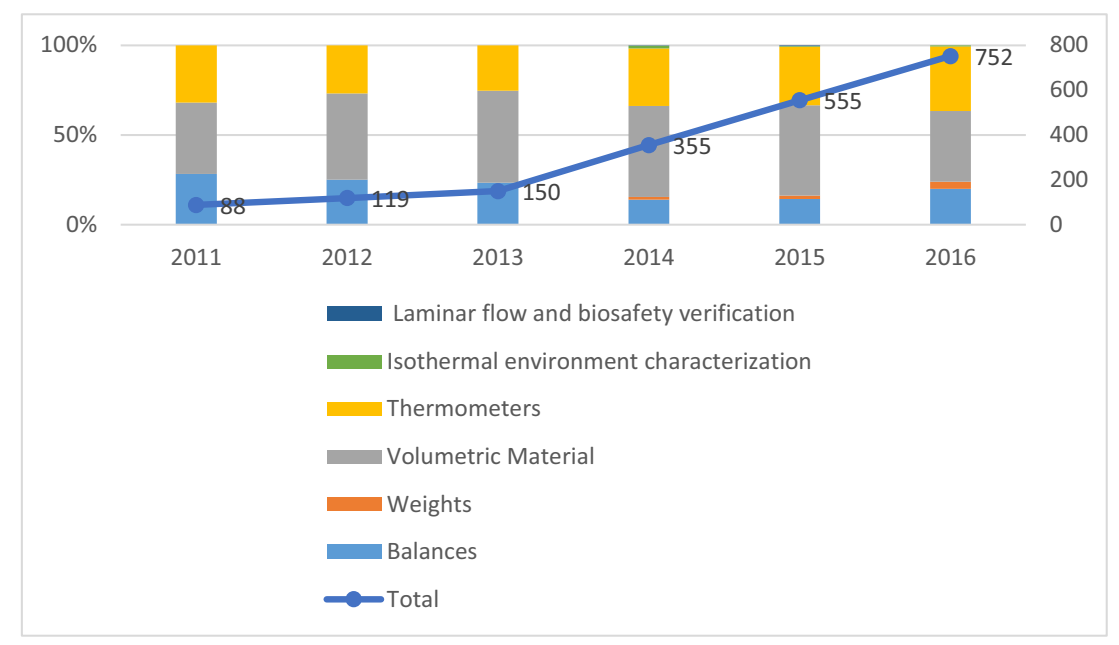

Finally, we analyze savings in performing internal calibrations rather than performing this service externally to INTA. For this analysis, an average cost of calibration services for different equipment and instruments was considered. From this analysis, it was found that during the period 2011-2016 INTA managed to optimize USD 214,313. Being the year 2016 the most significant with a saving of more than USD 85,000. This analysis showed that the calibrations of the electronic balances carry between 70 and $80 \%$ of the annual saving and this percentage has been maintained during the period 2011-2016. It was also observed that in the years 2014-2015 and 2016 the savings were increased by calibrations of volumetric material and thermometers. (Figs. 6 and 7 ).

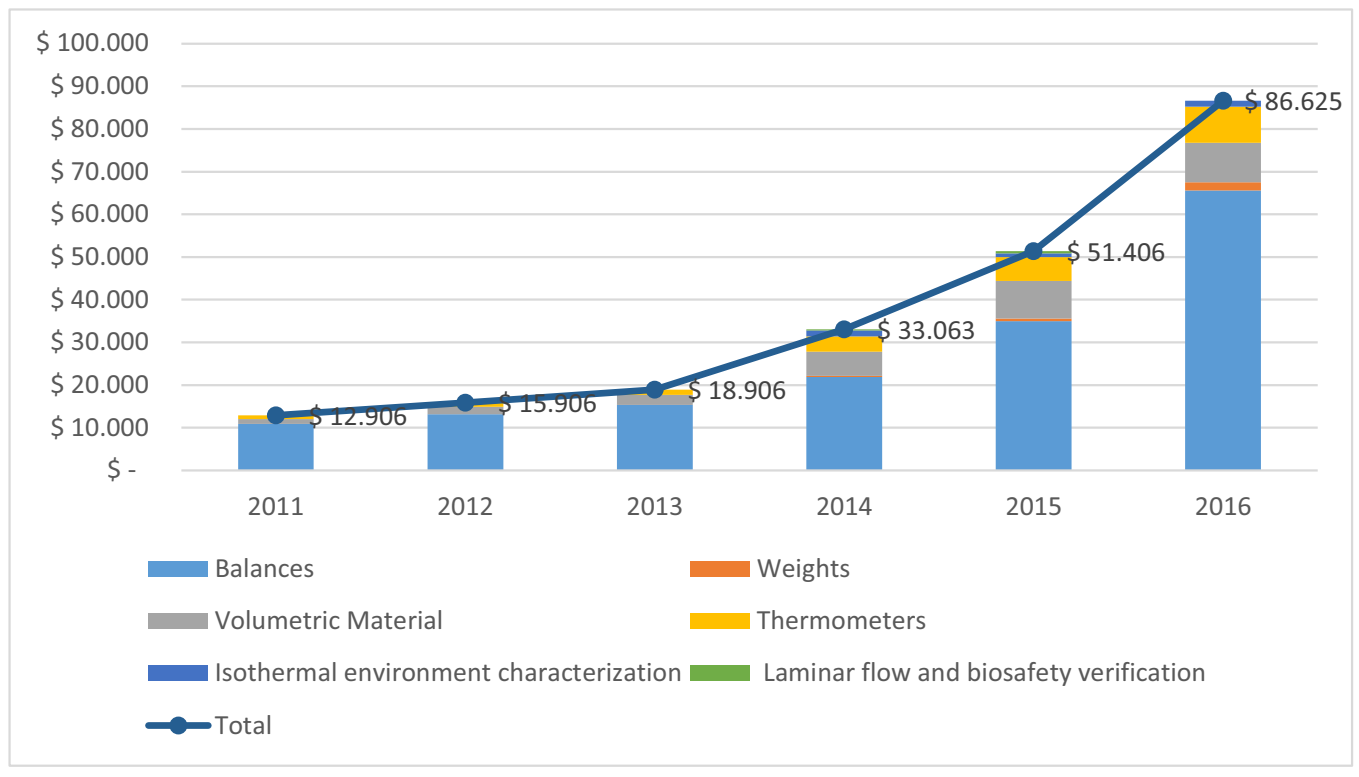

Fig. 6 Distribution of resource savings (in USD) by type of calibration in the period 2011-2016 


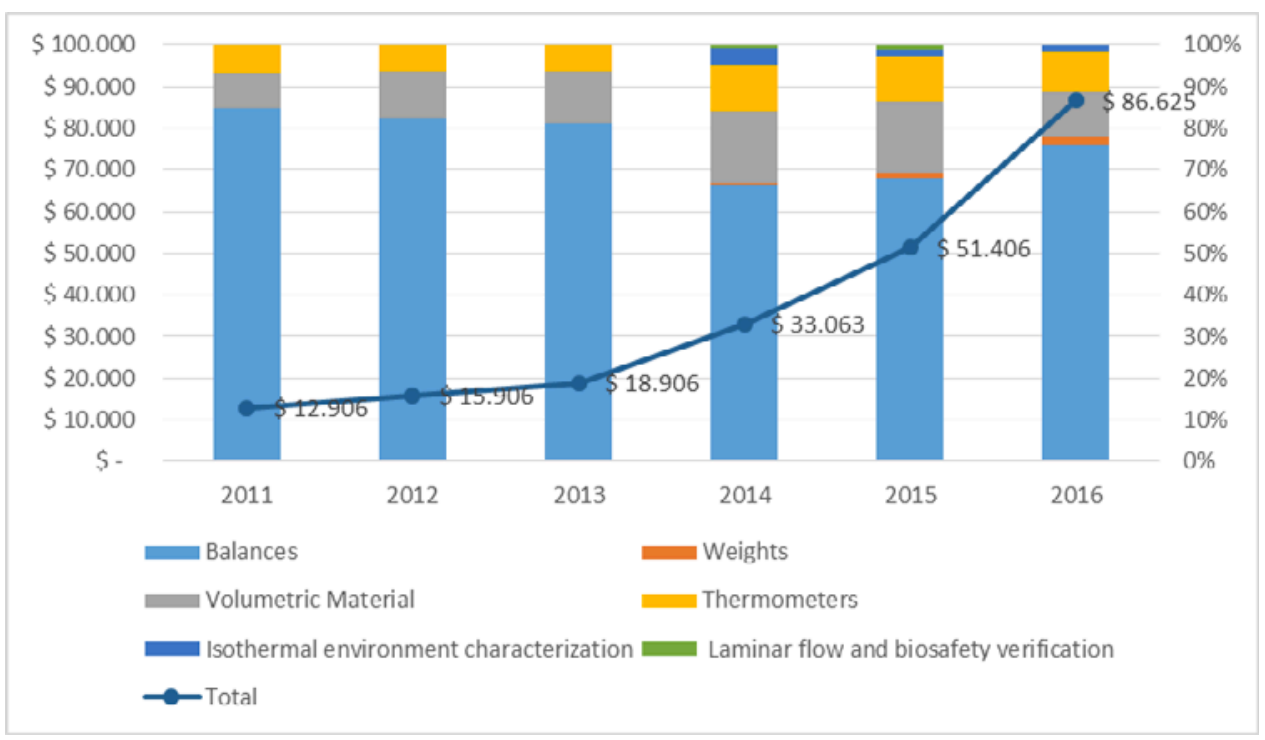

Fig. 7 Distribución del ahorro de recursos (en USD) y porcentaje de contribución de cada tipo de calibración en el periodo 2011-2016

\section{Implementation of a Quality Management System based on ISO 17025 in the LEAPMI and accreditation with the Argentine Accreditation Body}

The implementation of ISO / IEC 17025 in LEAPMI was carried out jointly and integrally with the existing quality management system ISO 9001: 2008 in the process and quality management. The implementation was simplified, as the management requirements expressed in ISO / IEC 17025 were largely solved with the ISO 9001 quality system already implemented.

To demonstrate the technical competence of the laboratory and to comply with the technical requirements of the standard, the laboratory performed controls on the factors determining the accuracy and reliability of the calibrations performed. These factors include elements from:

- of human factors

- of facilities and environmental conditions

- of the calibration methods, and of the validation of the methods

- of the equipment

- of the traceability of measurements

- of sampling

- of manipulation of calibration items

The degree to which the factors contribute to the overall uncertainty of the measurement differs considerably depending on the type of calibration. The laboratory took into account these factors in developing calibration methods and procedures, training and qualification of personnel, as well as in the selection and calibration of the equipment used, the manipulation of items and the control of environmental condition.

The implementation was carried out during 2011-2012, carrying out the first internal audit in December 2012. In November 2015 the application was submitted to the Argnentino Accreditation Body to accredit LEAPMI as a calibration laboratory. The scope requested was calibration of balances, volumetric material (automatic pipettes, flasks, pipettes and burettes), glass liquid thermometers and sensor - indicator thermometers.

Laboratory accreditation was achieved in May 2016 with the initially requested scope. (LC 041). 


\section{CONCLUSIONS}

The inclusion of an area of Metrology in governmental institutions such as INTA is strategic. According to the results observed, it is clear that the objectives set by the metrological area have been met. As it has been demonstrated that with the training and qualification of the personnel it is possible to train competent personnel to carry out internal calibrations. This is accompanied by the development of calibration software that allows and facilitates a calibration only by performing simple tests and without having to perform complex calculations.

For all this operation it is necessary to have traceable and calibrated standards to be used in the calibrations. In addition to this system is understood and supported by a quality management system following the guidelines of ISO / IEC 17025. Accreditation is the demonstration that LEAPMI and its staff are technically competent to perform calibrations.

Finally, it has been demonstrated that a system proposed in these conditions (internal calibrations) generates an optimization of resources and increases confidence in the results generated by the institution.

\section{REFERENCES}

ISO 9000, Quality management systems - Fundamentals and vocabulary

ISO/IEC 17000, Conformity assessment — Vocabulary and general principles

ISO 9001:2008. Quality Management Systems. Requirements.

ISO/IEC 17025:2005. General requirements for the competence of testing and calibration laboratories ISO/IEC Guide 99(JCGM 200:2012), International vocabulary of metrology — basic and general concepts and associated terms (VIM), issued by BIPM, IEC, IFCC, ILAC, ISO, IUPAC, IUPAP and OIML

INTA. 2004. PEI 2005-2015. El INTA que queremos. Plan Estratégico Institucional. 2005 - 2015.

Slepetis, C. 2011. Formación en Calidad. EI Caso INTA. Comunicaciones. VI IBEROLAB.

QMS documentes. Gerencia de Procesos y Calidad. INTA. 